\title{
Real-time characterization of particle-bound polycyclic aromatic hydrocarbons in ambient aerosols and from motor-vehicle exhaust
}

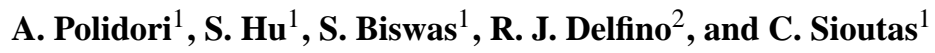 \\ ${ }^{1}$ Department of Civil and Environmental Engineering, University of Southern California, 3620 South Vermont Ave., Los \\ Angeles, CA, 90089, USA \\ ${ }^{2}$ Epidemiology Division, Department of Medicine, University of California Irvine, 100 Theory Dr., Suite 100, Irvine, CA \\ 92617, USA
}

Received: 30 October 2007 - Published in Atmos. Chem. Phys. Discuss.: 3 December 2007

Revised: 1 February 2008 - Accepted: 2 February 2008 - Published: 4 March 2008

\begin{abstract}
A photo-electric aerosol sensor, a diffusion charger, an Aethalometer, and a continuous particle counter were used along with other real-time instruments to characterize the particle-bound polycyclic aromatic hydrocarbon (p-PAH) content, and the physical/chemical characteristics of aerosols collected a) in Wilmington (CA) near the Los Angeles port and close to 2 major freeways, and $b$ ) at a dynamometer testing facility in downtown Los Angeles (CA), where 3 diesel trucks were tested. In Wilmington, the p-PAH, surface area, particle number, and "black" carbon concentrations were 4-8 times higher at 09:00-11:00 a.m. than between 17:00 and 18:00 p.m., suggesting that during rush hour traffic people living in that area are exposed to a higher number of diesel combustion particles enriched in p-PAH coatings. Dynamometer tests revealed that the p-PAH emissions from the "baseline" truck (no catalytic converter) were up to 200 times higher than those from the 2 vehicles equipped with advanced emission control technologies, and increased when the truck was accelerating. In Wilmington, integrated filter samples were collected and analyzed to determine the concentrations of the most abundant p-PAHs. A correlation between the total p-PAH concentration $\left(\mu \mathrm{g} / \mathrm{m}^{3}\right)$ and the measured photo-electric aerosol sensor signal (fA) was also established. Estimated ambient p-PAH concentrations (Average $=0.64 \mathrm{ng} / \mathrm{m}^{3} ;$ Standard deviation $=0.46 \mathrm{ng} / \mathrm{m}^{3}$ ) were in good agreement with those reported in previous studies conducted in Los Angeles during a similar time period. Finally, we calculated the approximate theoretical lifetime (70 years per 24-h/day) lung-cancer risk in the Wilmington area due to inhalation of multi-component p-PAHs and "black" carbon. Our results indicate that the lung-cancer risk is highest during rush hour traffic and lowest in the afternoon, and that the
\end{abstract}

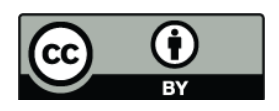

Correspondence to: C. Sioutas (sioutas@usc.edu) genotoxic risk of the considered p-PAHs does not seem to contribute to a significant part of the total lung-cancer risk attributable to "black" carbon.

\section{Introduction}

Polycyclic aromatic hydrocarbons (PAHs) are ubiquitous in the urban atmosphere and are typically produced from incomplete combustion of fossil fuels and organic compounds, or from high temperature pyrolytic processes involving any materials containing carbon and hydrogen (Bostrom et al., 2002). Important sources of PAHs include gasoline- and diesel-fuelled motor vehicles, biomass burning of agricultural and forest fuels, coal combustion, cigarette and wood smoke, and fossils fuels. Atmospheric PAHs are found in the gas-phase (if characterized by high vapor pressures) and in the particulate phase (if their vapor pressures is relatively low), or can partition between the gas- and the particlephases (Naumova et al., 2003). However, most PAHs, especially those with more than four aromatic rings, readily adsorb onto combustion aerosols (Harrison et al., 1996), and are predominantly associated with particles with an aerodynamic diameter smaller than 1-2 $\mu \mathrm{m}$ (Chetwittayachan et al., 2002).

The U.S. EPA has recently defined a list of 16 "Priority PAH Pollutants" based on their mutagenicity and carcinogenicity (IARC, 2005). For example, benzo (a) pyrene has been classified as a Group 1 carcinogen ("carcinogenic to humans") and cyclopenta (cd) pyrene, dibenz $(a, h)$ anthracene and dibenzo $(a, l)$ pyrene as Group 2 carcinogens ("probably carcinogenic to humans"). Fine and ultrafine particles (and, thus, the PAHs bound to them) can penetrate deeply into the bronchial and pulmonary part of the human respiratory system, where their deposit and accumulation

Published by Copernicus Publications on behalf of the European Geosciences Union. 
has been associated with short and long term health effects (Pope et al., 2002; 2004). Along with certain transition metals, PAHs and other organic hydrocarbons (e.g. quinones) have the potential to interact with airway epithelial cells and macrophages to generate reactive oxygen species (ROS), which have been linked to respiratory inflammation and other adverse health effects (Cho et al., 2005; Nel, 2005).

The detection of particle-bound PAHs (p-PAHs) has generally been accomplished through analytical procedures involving the collection of high mass loadings of particulate matter (PM) on filters, followed by analysis of the filter extract by mass spectrometry coupled with gas or liquid chromatography (GC/MS or LC/MS) (Schauer et al., 1996; Naumova et al., 2003). However, these methods require a laborious sample preparation, resolve only a fraction of the total PAH mass and, due to the amounts of PM that need to be collected to overcome analytical limits of detection, can only provide average atmospheric $\mathrm{p}-\mathrm{PAH}$ concentrations with low time resolutions (e.g., from several hours to a day). Because the processes leading to the production of PAHs are dynamic and occur on the time scale of minutes to a few hours, it is important to monitor their temporal variation in much shorter time intervals.

The photoelectric aerosol sensor (PAS) has been used alone or in conjunction with other continuous instruments to provide information on $\mathrm{p}-\mathrm{PAH}$ emissions in indoor and outdoor environments (Zhiqiang et al., 2000; Dunbar et al., 2001; Chetwittayachan et al., 2002; Wallace, 2005; Ott and Siegman, 2006), and from specific sources such as motor vehicles (Matter et al., 1999; Marr et al., 2004; Kelly et al., 2006), commercial and jet aircrafts (Herndon et al., 2005; Rogers et al., 2005), tobacco products, incense and candles, cooking sources, wood smoke and fireplaces (Ferge et al., 2005; Ott and Siegman, 2006). The PAS, the diffusion charging (DC) sensor, and the condensation particle counter (CPC) (all real-time particle instruments with a resolution $<10-\mathrm{s}$ ) have often been employed together to determine the relative fraction of nuclei versus accumulation mode particles in ambient combustion aerosols (Bukowiecki et al., 2002). The ratio between the PAS and the DC signals (PAS/DC) is of particular interest, because it provides a measure of the amount of p-PAHs per unit area of the active surface of particles (Ott and Siegman, 2006). Thus, the PAS/DC ratio may be directly related to the quantity of p-PAHs transported into the human respiratory tract. In a recent study conducted in the Mexico-City metropolitan area by Marr et al. (2006) an Aerodyne Aerosol Mass Spectrometer (AMS; Jimenez et al., 2003) was used for the first time to measure ambient concentrations of p-PAHs. The diurnal concentration patterns captured by aerosol photo-ionization (a PAS was run alongside the AMS) and aerosol mass spectrometry were generally consistent.

Motor vehicles account for as much as $90 \%$ of the p-PAH mass in the urban air of big metropolitan areas (Harrison et al., 1996; Bostrom et al., 2002). Thus, PAH levels could be significantly reduced by developing air pollution control strategies targeted at motor vehicles and, in particular, diesel trucks and older passenger cars that are not equipped with catalytic converters. To develop such PAH emissions reduction strategies, reliable information on the types and numbers of vehicles operating in urban areas, and on the PAH emissions rates for each vehicle type are needed. Obtaining representative measures of $\mathrm{PAH}$ emissions rates is difficult because this parameter is a function of the engine type, the state of repair of the engine, and the motor vehicle driving conditions (Schauer et al., 1999; 2002; Zielinska et al., 2004; Riddle et al., 2007a; 2007b).

In the present study, PAS, DC, CPC and other real-time measurements were taken: a) in Wilmington (CA), an area near the Los Angeles port and b) at the California Air Resources Board (CARB) Heavy-Duty Diesel Emissions Test Laboratory (HDETL), a dynamometer testing facility in downtown Los Angeles (CA). The ambient air in Wilmington is heavily influenced by a mix of industrial and gasoline/diesel-fuelled vehicle emissions. On the other hand, the dynamometer tests enabled us to characterize the exhausts of several individual types of diesel trucks, equipped with different emission control technologies, and operated under different driving conditions. The chemical composition, active surface area, and particle number concentrations measured by the PAS, DC, and CPC (respectively) were combined to provide information on the chemical and physical characteristics of the studied aerosols. These results were complemented with measurements of the particle size distribution and of the black carbon (BC) aerosol content to obtain further insights on the p-PAHs emitted by motor vehicles and other sources. Integrated 24-h Teflon filter samples were also collected in Wilmington, solvent extracted and analyzed by GC/MS to determine the relative concentrations of the most abundant p-PAHs found at the urban site. These outcomes were then used to establish a correlation between the total p-PAH concentration and the measured PAS signal (from fA to $\left.\mu \mathrm{g} / \mathrm{m}^{3}\right)$. Finally, we determined the approximate theoretical lifetime ( 70 years per $24-\mathrm{h} /$ day) lung-cancer risk in the Wilmington area due to inhalation of multi-component p-PAHs and BC by following a procedure that considers the benzo $(a)$ pyrene equivalent concentration $(\mathrm{B}(a) \mathrm{Peq})$, and $\mathrm{BC}$ as a surrogate for diesel combustion particle exposure (Sauvain et al., 2003).

\section{Experimental methods}

\subsection{Ambient sampling - the Wilmington site}

The first part of this study was conducted in Wilmington (CA), an urban area about $40 \mathrm{Km}$ south of downtown Los Angeles. The sampling site was located in one of the busiest parts of the Los Angeles port, less than $1.5 \mathrm{Km}$ east of the Harbor freeway (I-110), about $4.5 \mathrm{Km}$ west of the Long 
Beach Freeway (I-710), and close to several industrial facilities, such as power plants and oil refineries. The I-110 runs southbound through the Harbor Gateway, a two-mile wide north-south corridor that was annexed by the city of Los Angeles specifically to connect San Pedro, Wilmington and the port of Los Angeles with the rest the city. Both freeways are the principal means for transferring freight from the port of Los Angeles to rail yards and warehouses further inland, and they are notoriously congested, especially during rush hour traffic. Although the majority of the I-710 freeway traffic is comprised of light duty gasoline-powered cars, about $15-20 \%$ of the total number of vehicles is typically represented by heavy duty diesel powered trucks (Ntziachristos et al., 2007a, 2007b) which are expected to be major sources of combustion related pollutants, including BC and semivolatile and p-PAHs.

Our sampling station was set up inside a 10-m long mobile trailer provided by the South Coast Air Quality Management District (AQMD) with a few instruments deployed inside a rigid enclosure situated right outside the trailer. All continuous data were collected during an intensive field campaign conducted between 1 May and 29 May 2007. A photoelectric aerosol sensor (PAS; model PAS2000CE; EcoChem Analytics, Murrieta, CA) and a Nano-particle Surface Area Monitor (NSAM; Model 3550, TSI Inc., Shoreview, MN) were used to monitor the temporal variation of p-PAHs and the particle active surface, respectively, with a time resolution $\leq 10$-s. The principle of operation of the PAS and of the NSAM, which is essentially a diffusion charger, (Ntziachristos et al., 2007c) is very similar. The fundamental difference between the two is the particle charging mechanism: the PAS employs photo-ionization by mean of ultraviolet light (Niessner, 1986; Matter et al., 1999; Jung and Kittelson, 2005), whereas the NSAM utilizes diffusion charging through a corona discharge (Fissan et al., 2007; Ntziachristos et al., 2007c). In both instruments, positively charged particles are collected on a filter, generating a current that is measured by an electrometer (for technical details see Matter et al., 1999, and Ntziachristos et al., 2007c). Previous studies have demonstrated that the PAS is most sensitive to p-PAHs deposited/bound on the particle surface and less responsive to those covered by layers of other aerosol compounds (Marr et al., 2004, 2006). The NSAM has been designed and calibrated by the manufacturer to provide a signal (in fA) whose intensity is directly proportional to the human lung-deposited surface area of particles (a calibration constant is used to convert fA to $\mu \mathrm{m}^{2} / \mathrm{cm}^{3}$ ).

A dual-beam Aethalometer (Anderson RTAA-900, Andersen Instruments Inc.) was used to determine $\mathrm{PM}_{2.5} \mathrm{BC}$ concentrations with a time interval of 5-min. This instrument uses the optical attenuation of $880 \mathrm{~nm}$ wavelength light to measure the $\mathrm{BC}$ mass concentration as particles are collected on a quartz fiber filter strip. Continuous (1-min) ambient particle number $(\mathrm{PN})$ concentrations were measured using a condensation particle counter (CPC, model 3022A, TSI
Inc., Shoreview, MN) that was serviced and calibrated by the manufacturer prior the beginning of this study. Wind direction/speed, temperature and humidity were recorded with a weather station (Wizard III, Weather Systems Company, San Jose, CA, USA). For comparison purposes, 1-h averages were calculated from all continuous data.

A few studies have revealed a good correlation between the PAS signal (also in fA) and the concentration of 1115 of the most abundant p-PAHs on concurrently collected aerosols samples (McDow et al., 1990; Hart et al., 1993; Siegmann and Siegmann, 2000; Chetwittayacha et al., 2002). The correlation between the PAS response and the PAH concentration is generally very high $\left(R^{2} \geq 0.80\right)$ for a wide variety of sources, including: oil burner exhaust, parking garage air, cigarette smoke, burners, and urban aerosols, indicating that it is possible to calibrate the PAS signal to estimate p-PAH concentrations in several environments. However, since different locations are characterized by a different mix of PAH sources, the calibration of the PAS is site-specific and time dependent. The sensor's response has also been reported to be linearly correlated $\left(R^{2}=0.82\right)$ with bacterial genotoxicity (Wasserkort et al., 1996).

From 11 June to 24 June 2007, we collected 10 daily (24h) integrated ambient $\mathrm{PM}_{2.5}$ filter samples at the Wilmington site by using only the $2.5 \mu \mathrm{m}$ cutpoint stage and the after filter of a Micro-Orifice Uniform Deposit Impactors (MOUDI, MSP, Inc., Minneapolis, MN) operating at $301 \mathrm{pm}$. All impaction substrates ( $37 \mathrm{~mm}$ PTFE Teflon filters; $2 \mathrm{~m} \mu \mathrm{m}$ pore, Gelman Science, Ann Arbor, MI) were used as provided by the manufacturer without any pre-treatment. Each integrated filter sample was extracted with solvents and analyzed by GC/MS for the concentration of the most abundant p-PAHs typically found in urban environments. Details about sample preparation and GC/MS analysis have been previously described by Sheesley et al. (2000, 2004). The PAS signal (fA) measured in Wilmington was then calibrated against the sum of the detected p-PAH concentrations $\left(\mathrm{ng} / \mathrm{m}^{3}\right)$. From a similar calibration procedure, Marr et al. $(2004,2006)$ estimated the uncertainty of the PAS response to be around $20 \%$.

\subsection{Motor-vehicle emissions sampling - the CARB dy- namometer facility}

The second part of this work was conducted at the California Air Resource Board-Heavy-Duty Emissions Testing Laboratory (CARB-HDETL), located at the Los Angeles Metropolitan Transportation Authority (MTA) in downtown Los Angeles. The sampling train included heavy-duty dynamometer chassis, constant volume sampling (CVS) dilution tunnel, and aerosol samplers. Details about this facility and its operation are described elsewhere (Ayala et al., 2002).

With the exception of the "baseline" vehicle (not equipped with any catalytic converter) the other 2 tested heavy duty diesel trucks, a Vanadium-based SCRT vehicle and a Zeolitebased SCRT truck, were equipped with advanced emission 


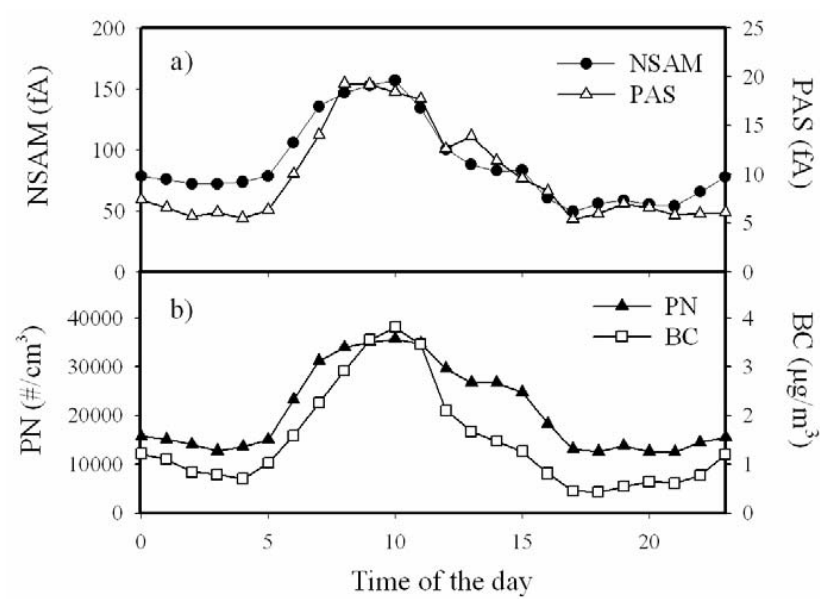

Fig. 1. Average hourly diurnal profiles of the photoelectric aerosol sensor (PAS) and nano-particle surface area monitor (NSAM) signals (a), and of the black carbon (BC) and particle number (PN) concentrations (b) measured at the Wilmington site in May 2007.

control technologies that allowed them to meet the state of California 2007 PM and 2010 NOx emission standards. SCRT is an integrated system of selective catalytic reduction (SCR) and continuously regenerating trap (CRT) designed to reduce both PM and NOx emissions. Details about all 3 vehicles are reported in Table 1. Similarly to the Wilmington (outdoor) site, several real-time instruments were employed to fully characterize the motor-vehicle emissions downstream of the CVS. PN concentration data was obtained by using a CPC (Model 3025A, TSI Inc., Shoreview, MN), while the particle size distribution was measured by an Engine Exhaust Particle Sizer (EEPS 3090, TSI Inc., Shoreview, MN) and a differential mobility spectrometer (DMS 500, Cambustion Ltd., Cambridge, UK). The EEPS and DMS measured the particle size distribution in the size range from $5.6 \mathrm{~nm}$ to $560 \mathrm{~nm}$ and from $5 \mathrm{~nm}$ to $1000 \mathrm{~nm}$, respectively. The physical (surface area) and chemical (pPAHs) characteristics of the particles in the exhausts of the tested vehicles were monitored by an Electrical Aerosol Detector (EAD 3070A, TSI Inc., Shoreview, MN) and a Photoelectric Aerosol Sensor (PAS 2000CE, EcoChem), respectively. Additional measurements (not discussed in the current work) included PN and PAH concentrations of the volatile fraction of the emissions by mean of a different CPC (Model 3022 A, TSI Inc., Shoreview, MN) and PAS (Model 2000, EcoChem), respectively, located downstream of 2 thermal denuders.

All vehicles were tested under two different driving cycles (well defined speed versus time traces, usually displayed on a computer monitor, which the driver attempts to follow) to simulate various real world conditions: 1) steadystate cruise, and 2) transient. During steady-state cruise tests, the vehicles were operated at a speed of $50 \mathrm{mph}$ for $45 \mathrm{~min}$, whereas in a transient cycle they were driven through a series of accelerations and decelerations runs at different time intervals, according to the Urban Dynamometer Driving Schedules (UDDS) for heavy-duty vehicles (see "Code of Federal Regulations" for details). Each cycle was repeated until the collection substrates were loaded with enough mass for chemical and toxicological analysis. Ultra-low sulfur diesel (ULSD) with a sulfur content $<15 \mathrm{ppm}$ (provided by BP) was used as test fuel.

\section{Results}

\subsection{Descriptive analysis}

As shown in Fig. 1a and b, the average hourly diurnal profiles of the PAS, NSAM, BC and PN concentration data collected in Wilmington were very similar. All ambient measurements peaked during morning rush hour traffic because of increased motor-vehicle emissions from both light and heavy duty vehicles, reached a minimum late in the afternoon, and slightly increased again at night because of a lowered mixing height, increased atmospheric stability, and possible condensation of the most volatile species (e.g. organic vapors from vehicles' exhausts) onto the existing particles due to temperature decrease. The PAS and NSAM signals and the PN and $\mathrm{BC}$ concentrations were 4 to 8 times higher between 09:00 and 11:00 a.m. than at 17:00-18:00 p.m., indicating that during traffic periods commuters are exposed to a substantially higher number of combustion particles enriched in p-PAH coatings. Similar results were obtained by Ning et al. (2007) at a typical urban site in the Los Angeles area, where the atmospheric concentrations of organic species such as alkanes, hopanes and steranes, and p-PAHs were up to 6 times higher during traffic periods than throughout the rest of the day. These findings are important given the mutagenicity and carcinogenicity of these organic compounds.

The physical and chemical characteristics of particles emitted by motor vehicles are highly dependent on the age and type of car/truck (gasoline- or diesel-fuelled), the presence or absence of emission control technology, and the driving conditions (engine load) (Zielinska et al., 2004; Riddle et al., 2007a, 2007b). Figure 2 shows time series of the PAS and EAD (DC) signals for the "baseline" (2a) and the Zeolitebased SCRT vehicles (2b) operated in UDDS mode; both trucks are diesel-fuelled, although the former is not equipped with any type of catalytic trap. The inverse correlation between PAS and EAD signals observed in Figure 2b suggests that, although the Zeolite-based SCRT exhaust was dominated by photo-emitting material, at times the production of particles with a very high active surface area (corresponding to the EAD peaks) suppressed the PAS response. In contrast, the PAS and EAD signals of the "baseline" vehicle (2a) were very well correlated at all times, indicating that its emissions (much higher than those from the Zeolite-based SCRT truck) were characterized by the presence of relatively large 
Table 1. Details about the 3 tested diesel trucks: Vanadium-based SCRT (V-SCRT), Zeolite-based SCRT (Z-SCRT), and “Baseline” vehicles.)

\begin{tabular}{|c|c|c|c|c|c|c|}
\hline Name/Make/Engine Model/Year & Miles & 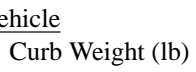 & GVWR (lb)* & Tested Wt (lb) & After treatment type & Dilution; CVS flow $(\mathrm{cfm})^{* *}$ \\
\hline $\begin{array}{l}\text { V-SCRT/Kenworth/ } \\
\text { Cummins M11, reflashed } \\
(11 \mathrm{~L}) / 1998\end{array}$ & $\sim 360000$ & 26640 & 80000 & 53320 & Vanadium based SCRT & 2600 (UDDS) \\
\hline $\begin{array}{l}\text { Z-SCRT/Kenworth/ } \\
\text { Cummins M11, reflashed } \\
(11 \mathrm{~L}) / 1998\end{array}$ & $\sim 360000$ & 26640 & 80000 & 53320 & Zeolite based SCRT & 2600 (UDDS) \\
\hline $\begin{array}{l}\text { Baseline/Kenworth/ } \\
\text { Cummins M11, reflashed } \\
(11 \mathrm{~L}) / 1998\end{array}$ & $\sim 374000$ & 26640 & 80000 & 53320 & None & 2600 (UDDS) \\
\hline
\end{tabular}

*GVWR: gross vehicle weight rating. Maximum allowable total weight of the vehicle/loaded trailer on the road. *Dilution flow through the constant volume sampler (CVS) (total volume of mixture air in the CVS).

a)

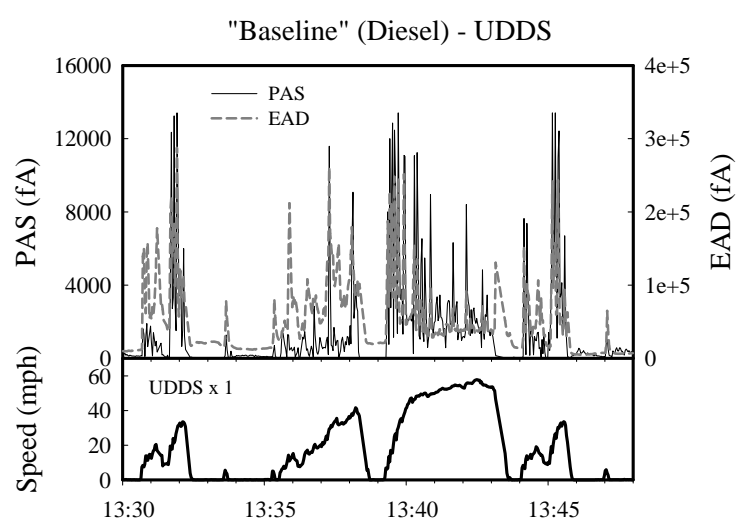

b)

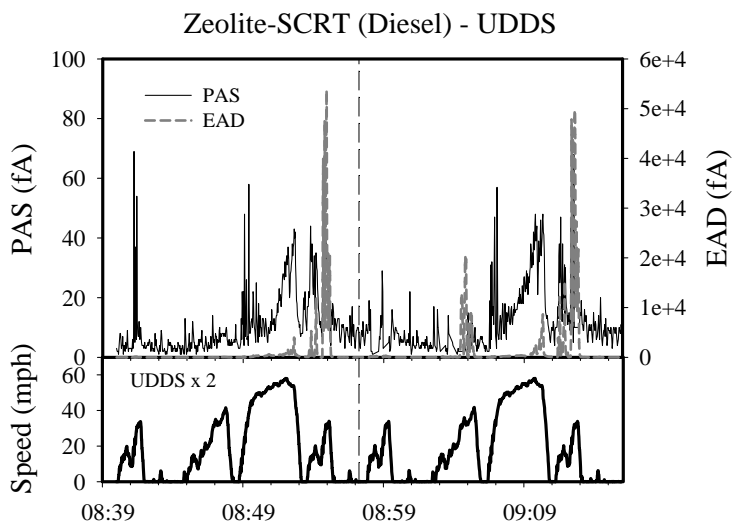

Fig. 2. Time series of the PAS and EAD signals (fA) for the "baseline" (a) and the Zeolite-based SCRT (b) vehicles, both operating in UDDS mode. Speed profiles during typical UDDS cycles are also reported.

particles coated with one or more layers of photo-emitting material (e.g. p-PAHs). Further details about the dynamometer test results are discussed in the following sections.
3.2 Correlations among the responses of various instruments

PAS versus DC plots are convenient ways to identify the characteristic properties of different types of combustion aerosols such as diesel particles, cigarette smoke, candle smoke, wood fire, etc. (Matter et al., 1999; Bukowiecki et al., 2002; Ott and Siegman, 2006). Since the responses of both instruments are a function of the aerosol surface area concentration, the slope of the regression line of these plots is related to the capability of the surface to undergo photoelectric charging, which depends on the nature of the surface material. Typically, the presence of a high concentration of nucleation mode particles (diameter $<50 \mathrm{~nm}$ ) results in a low PAS signal because these are non-photo emitting (Matter et al., 1999; Baltensperger et al., 2002); thus a low (or even negative) slope for the PAS versus DC plot is obtained in this situation. On the other hand, when the aerosol size distribution is dominated by accumulation mode particles (in the context of emissions testing usually defined as particles with an aerodynamic diameter $>50-60 \mathrm{~nm}$ ) such as diesel emissions, a highly positive slope is obtained. The presence of aged accumulation mode particles in the analyzed aerosol also tends to suppress the PAS signal, because these are generally coated with condensable species with weak photo-emitting properties, such as sulfate, nitrate and certain semi-volatile hydrocarbons (Bukowiecki et al., 2002).

As shown in Fig. 3a, the PAS versus NSAM plot obtained in Wilmington is characterized by measurements that are continuously distributed between two boundaries. This indicates the presence of both nucleation/aged accumulation mode (lower boundary) and fresh accumulation mode (upper boundary) particles; the majority of data-points was scattered in between. This situation is typical of any urban environment and has been observed in previous studies conducted in the US (Bukowiecki et al., 2002; Ott and Siegman, 2006) and in other countries (Chetwittayachan et al., 2002; Marr et al., 2004). Analysis of the slopes from the linear regressions of time-segregated PAS 


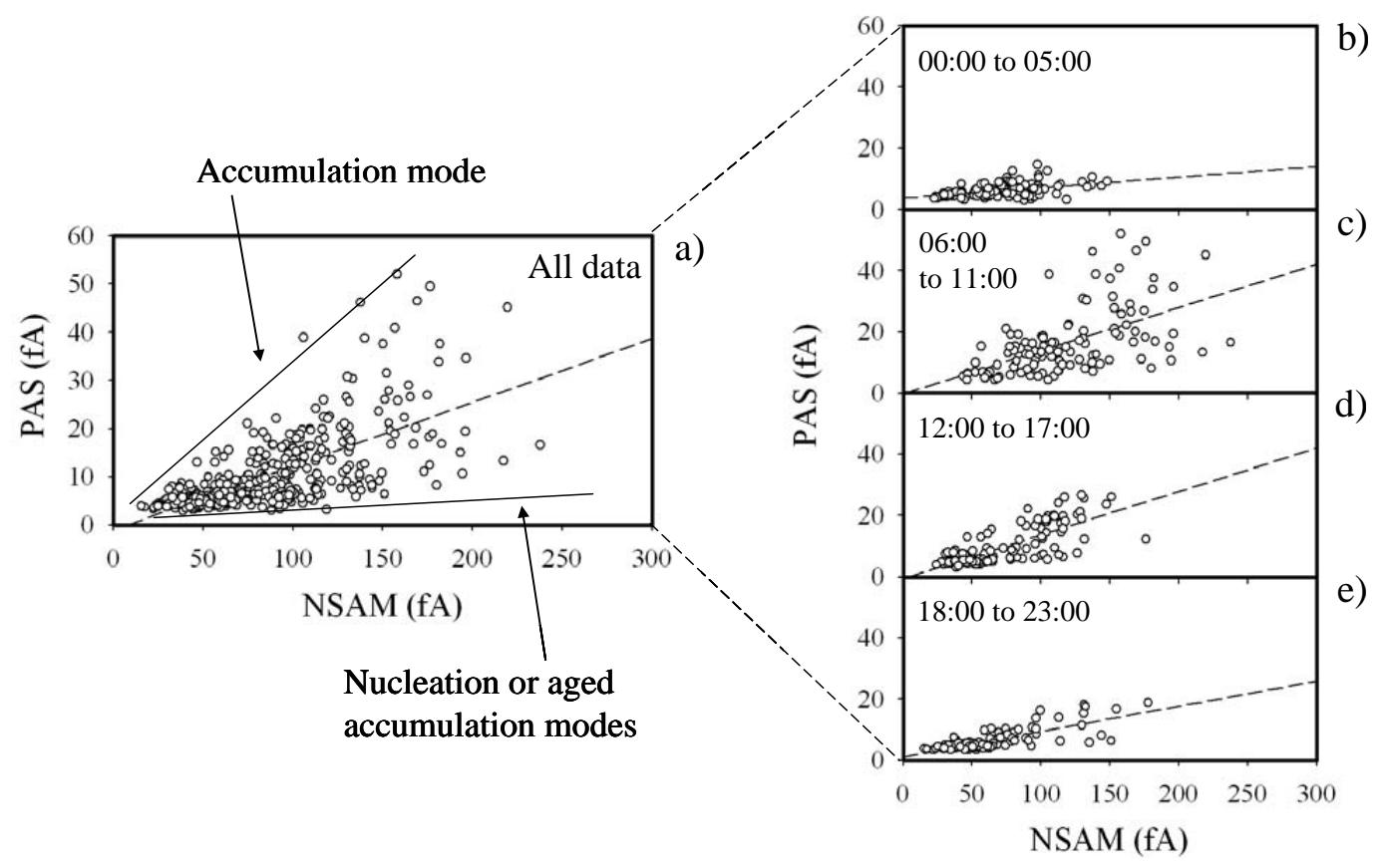

Fig. 3. PAS vs NSAM plots considering all measurements obtained at the Wilmington site in May 2007 (a), and the corresponding timesegregated data (b to e). Regression equations and correlation coefficients $\left(R^{2}\right)$ were: (a) $\mathrm{y}=0.13 \times-1.03, R^{2}=0.47 ;(\mathrm{b}) \mathrm{y}=0.04 \times+3.69$, $R^{2}=0.21 ;$ (c) $\mathrm{y}=0.14 \times-0.18, R^{2}=0.31 ;$ (d) $\mathrm{y}=0.14 \times-0.59 ; R^{2}=0.57 ;$ (e) $\mathrm{y}=0.08 \times+1.14, R^{2}=0.60$.

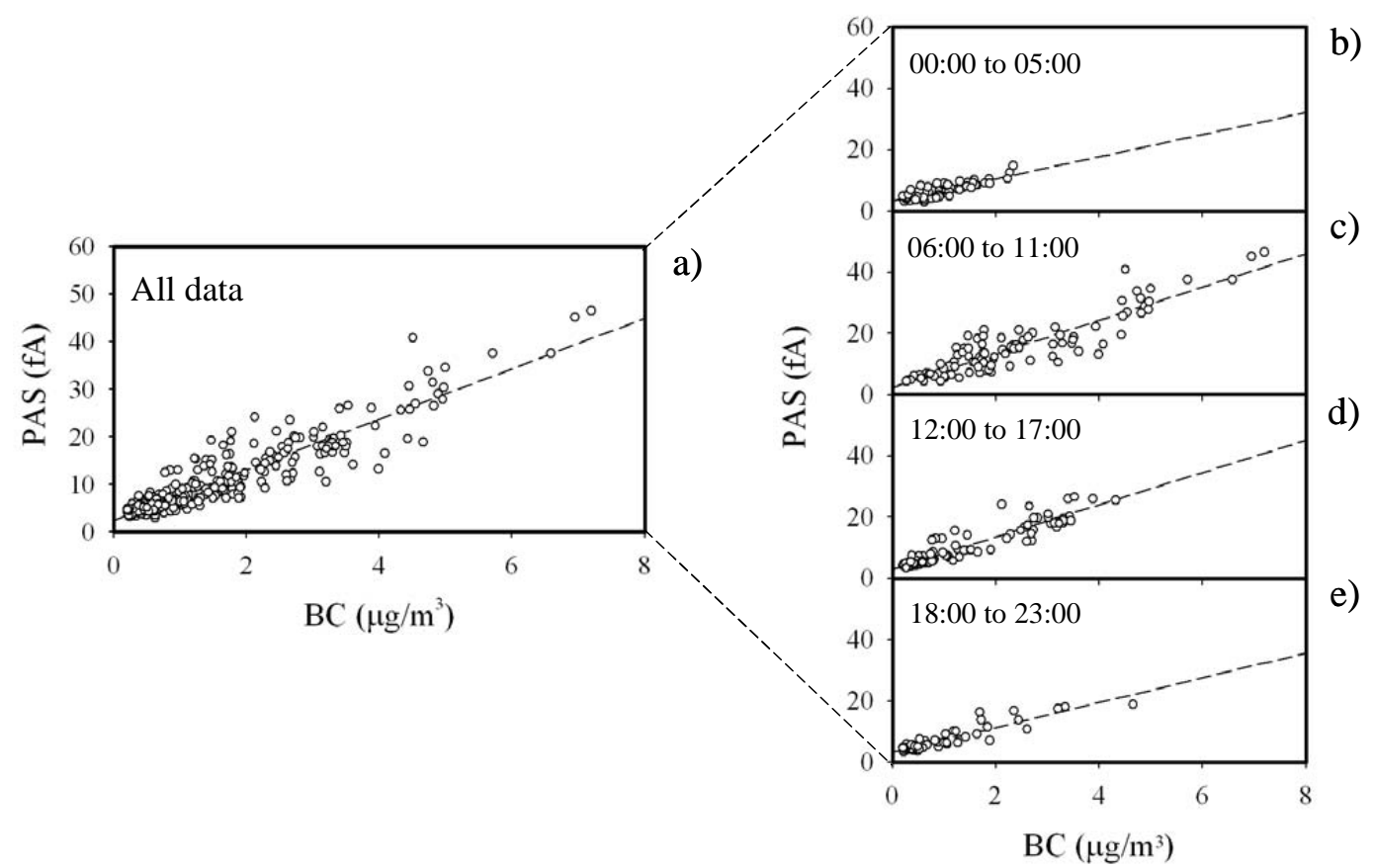

Fig. 4. PAS vs BC plots considering all measurements obtained at the Wilmington site in May 2007 (a), and the corresponding timesegregated data (b to e). Regression equations and correlation coefficients $\left(R^{2}\right)$ were: (a) $\mathrm{y}=5.31 \times+2.48, R^{2}=0.86$; $(\mathrm{b}) \mathrm{y}=3.62 \times+3.23$, $R^{2}=0.69 ;$ (c) $\mathrm{y}=5.44 \times+2.52, R^{2}=0.82 ;$ (d) $\mathrm{y}=5.27 \times+2.99 ; R^{2}=0.86 ;$ (e) $\mathrm{y}=4.04 \times+3.29, R^{2}=0.84$. 
18:00 to 23:00 p.m. (Fig. 3e) $\left(\right.$ Slope $\left._{(18: 00-23: 00)}=0.08\right)$ were likely to be dominated by aged accumulation mode particles covered with non-photo emitting material (e.g. nitrate, sulfate, water, hydrocarbons, etc.) and, to a lesser extent, nucleation mode particles. Conversely, an increase in the regression slopes observed in Fig. $3 \mathrm{c}$ and d suggests that aerosols produced during rush hour traffic (06:00 to 11:00 a.m.) $\left(\right.$ Slope $\left._{(06: 00-11: 00)}=0.14\right)$ and early in the afternoon $(12: 00$ to $17: 00)\left(\operatorname{Slope}_{(12: 00-17: 00)}=0.14\right)$ had the highest concentrations of freshly emitted accumulation mode particles, probably in the form of BC covered with p-PAHs. Diesel vehicles have been found to yield the highest PAS/DC readings on roadways measurements conducted in California by Ott and Siegman (2006), most likely because diesel fuel is characterized by a higher PAH content than gasoline fuel (Lee et al., 1995). In addition, several roadside, road tunnel, and chassis dynamometer studies have demonstrated that the emission factors of p-PAHs (especially of light molecular weight species such as fluoranthene, pyrene, and benzo(ghi)fluoranthene in particular) from heavy-duty diesel vehicles are significantly higher than those from lightduty gasoline vehicles (Schauer et al., 1999; Zielinska et al., 2004; Phuleria et al., 2006; Fujita et al., 2007; Ning et al., submitted). Overall, the fact that the slope of the PAS versus DC plot increases during rush hour traffic and decreases at nighttime is a clear indication of the effect of variable particle chemical composition throughout the day as a result of different sources and formation mechanisms.

As illustrated in Fig. 4a to e, the PAS signal and the $\mathrm{BC}$ concentration in Wilmington were very well correlated during the course of the day $\left(R_{\text {(alldata) }}^{2}=0.86 ; \quad R_{(00: 00-05: 00)}^{2}=0.69 ; \quad R_{(06: 00-11: 00)}^{2}=0.82\right.$; $\left.R_{(12: 00-17: 00)}^{2}=0.86 ; R_{(18: 00-23: 00)}^{2}=0.84\right)$, and the magnitude of the regression slopes did not vary significantly from early in the morning to late at night Slope $_{(00: 00-05: 00)}=3.62$; Slope $_{(06: 00-11: 00)}=5.44 ; \quad \operatorname{Slope}_{(12: 00-17: 00)}=5.27$; Slope $\left._{(18: 00-23: 00)}=4.04\right)$. These are all indications that p-PAHs and BC particles at this urban site have a common origin, and that diesel combustion emissions probably represent the main source of p-PAHs in the Wilmington area. These results confirm those obtained by Chetwittayachan et al. (2002) in Tokyo and Bangkok and by other researcher in different metropolitan areas where air pollution is dominated by traffic emissions (Marr et al., 2004, 2006). A summary of the slopes, intercepts and $R^{2}$ for the correlations among all measurements taken at the Wilmington site are reported in Table 2.

The correlation coefficient and regression slopes of the PAS versus EAD (DC) plots obtained from the dynamometer tests were a strong function of the presence or absence of emission control technologies in the tested vehicles and of the driving conditions. An example of these types of plots for the "baseline" vehicle operated in UDDS cycle is reported in Fig. 5. Similarly to what was observed in Wilmington,
Table 2. Summary of the slopes, intercepts and $R^{2}$ for the correlations among all of the measured data obtained at the Wilmington site.

\begin{tabular}{|c|c|c|c|c|}
\hline Correlation & Time period & Slope & Intercept & $R^{2}$ \\
\hline \multirow{5}{*}{$\begin{array}{l}\text { PAS (fA) vs. } \\
\text { NSAM (fA) }\end{array}$} & All data & 0.132 & -1.03 & 0.48 \\
\hline & 00:00 to $05: 00$ & 0.035 & 3.69 & 0.21 \\
\hline & $06: 00$ to $11: 00$ & 0.141 & -0.18 & 0.31 \\
\hline & $12: 00$ to $17: 00$ & 0.142 & -0.59 & 0.57 \\
\hline & $18: 00$ to $23: 00$ & 0.082 & 1.14 & 0.60 \\
\hline \multirow{5}{*}{$\begin{array}{l}\text { PAS (fA) vs. } \\
\text { PN }\left(\# / \mathrm{cm}^{3}\right)\end{array}$} & All data & 0.00050 & 0.34 & 0.51 \\
\hline & 00:00 to $05: 00$ & 0.00010 & 4.45 & 0.11 \\
\hline & $06: 00$ to $11: 00$ & 0.00050 & 1.09 & 0.35 \\
\hline & $12: 00$ to $17: 00$ & 0.00030 & 2.44 & 0.31 \\
\hline & $18: 00$ to $23: 00$ & 0.00030 & 1.98 & 0.62 \\
\hline \multirow{5}{*}{$\begin{array}{l}\text { NSAM (fA) vs. } \\
\text { PN }\left(\# / \mathrm{cm}^{3}\right)\end{array}$} & All data & 0.00330 & 16.66 & 0.62 \\
\hline & 00:00 to $05: 00$ & 0.00430 & 14.53 & 0.69 \\
\hline & $06: 00$ to $11: 00$ & 0.00390 & 11.28 & 0.57 \\
\hline & $12: 00$ to $17: 00$ & 0.00210 & 23.22 & 0.51 \\
\hline & $18: 00$ to $23: 00$ & 0.00360 & 10.96 & 0.66 \\
\hline \multirow{5}{*}{$\begin{array}{l}\mathrm{BC}\left(\mu \mathrm{g} / \mathrm{m}^{3}\right) \text { vs. } \\
\text { PN }\left(\# / \mathrm{cm}^{3}\right)\end{array}$} & All data & 0.00010 & -0.68 & 0.63 \\
\hline & 00:00 to $05: 00$ & 0.00005 & 0.24 & 0.29 \\
\hline & $06: 00$ to $11: 00$ & 0.00010 & -1.21 & 0.70 \\
\hline & $12: 00$ to $17: 00$ & 0.00006 & -0.10 & 0.43 \\
\hline & $18: 00$ to $23: 00$ & 0.00010 & -0.74 & 0.65 \\
\hline \multirow{5}{*}{$\begin{array}{l}\mathrm{BC}\left(\mu \mathrm{g} / \mathrm{m}^{3}\right) \mathrm{vs} . \\
\text { NSAM (fA) }\end{array}$} & All data & 0.029 & -1.06 & 0.80 \\
\hline & 00:00 to $05: 00$ & 0.027 & -1.10 & 0.67 \\
\hline & $06: 00$ to $11: 00$ & 0.030 & -1.18 & 0.78 \\
\hline & $12: 00$ to $17: 00$ & 0.027 & -0.75 & 0.70 \\
\hline & $18: 00$ to $23: 00$ & 0.027 & -0.96 & 0.82 \\
\hline \multirow{5}{*}{$\begin{array}{l}\text { PAS (fA) vs. } \\
\mathrm{EC}\left(\mu \mathrm{g} / \mathrm{m}^{3}\right)\end{array}$} & All data & 5.307 & 2.48 & 0.86 \\
\hline & 00:00 to $05: 00$ & 3.619 & 3.23 & 0.69 \\
\hline & $06: 00$ to $11: 00$ & 5.437 & 2.52 & 0.82 \\
\hline & $12: 00$ to $17: 00$ & 5.265 & 2.99 & 0.86 \\
\hline & $18: 00$ to $23: 00$ & 4.042 & 3.29 & 0.84 \\
\hline
\end{tabular}

the PAS versus NSAM plot consists of data-points that are uniformly distributed between two boundaries (Fig. 5a). However, when measurements were segregated based on the accelerating conditions during the test, the slope of the regression line changed distinctively from negative $(\min =-0.008)$ to positive $(\max =0.08)$ as the vehicle speed increased from 0 to $57 \mathrm{mph}$ (Fig. 5b), indicating a substantial variation in the surface properties of the particles present in the examined exhaust (only regression slopes are shown in Fig. 5b). Most importantly, the particle size distribution shifted from nucleation to accumulation mode, going from the lower (Fig. 5c) to the higher (Fig. 5d) speed ranges, highlighting the fact that the "baseline" truck had higher p-PAH emissions at higher driving speeds. Coagulation and condensational growth were likely to be the mechanisms associated with the observed increase in particle diameter. 
a)

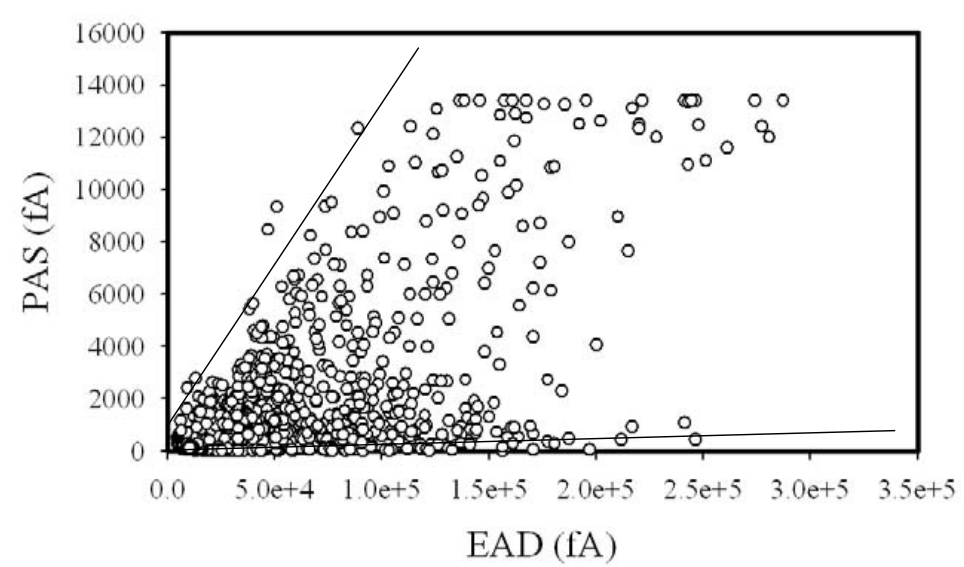

b)

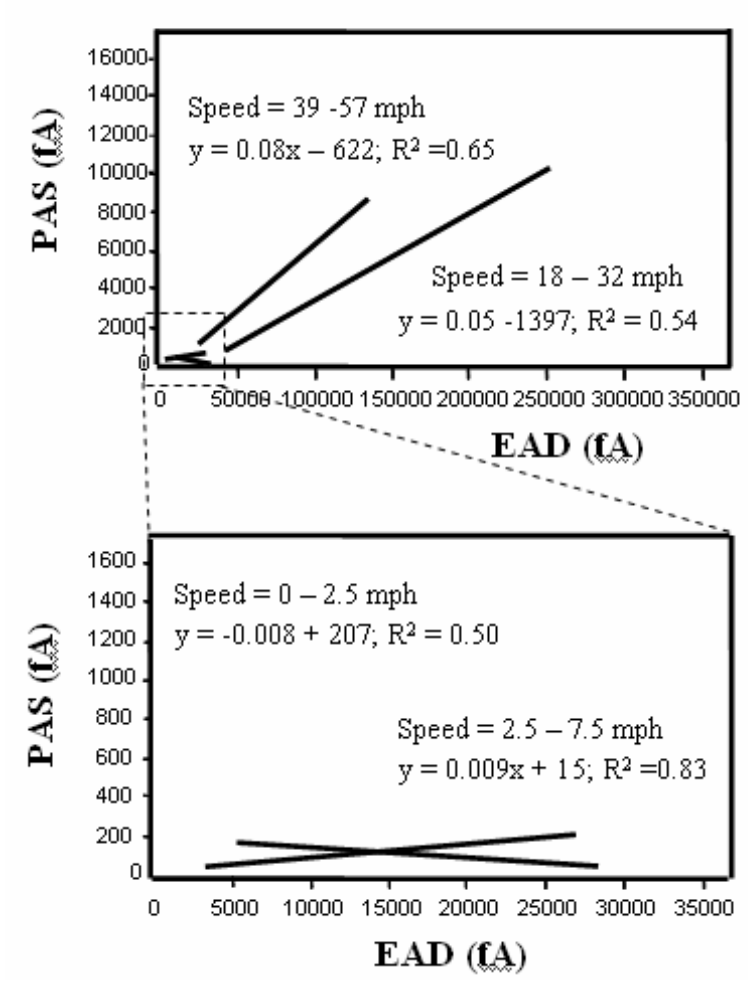

c)

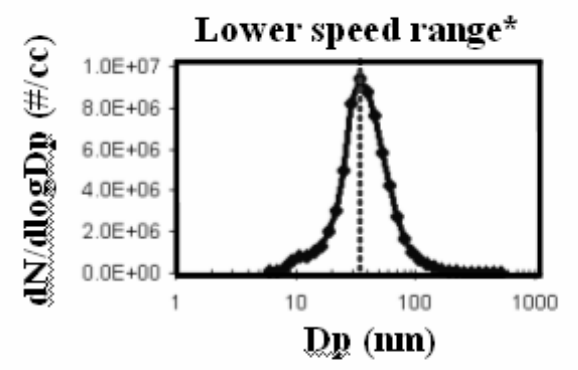

d)

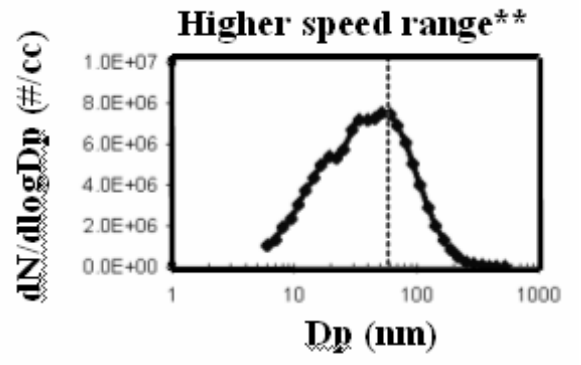

Fig. 5. PAS vs EAD plots for the "baseline" vehicle operated in UDDS mode considering all measurements (a) and data segregated by different acceleration cycles (b). The particle size distribution is also reported for lower (d) and higher (c) speed ranges.

Very different results were observed for the PAS versus EAD plots of vehicles equipped with SCRT emission control technologies and operating in the UDDS cycle. Distinct spikes in the PAS signal were clearly detected when plotting all data-points collected while testing the catalyst-equipped vehicles (data not shown). Unlike the "baseline" vehicle, the highest and the lowest PAS signals (and regression slopes) were observed at start-up (Slope (Vanadium) $)_{\text {Start-up }}=0.56$; Slope $\left.(\text { Zeolite) })_{\text {Start-up }}=1.725\right)$ and during the acceleration mode $\left(\right.$ Slope $(\text { Vanadium })_{\text {Acceleration }}=0.0004$;

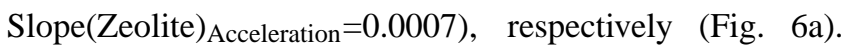
Also, a lower relative contribution of nucleation mode particles to the measured particle number concentration was observed at start-up (Fig. 6b), probably because the engine temperature was not high enough to activate the catalyst (Vanadium or Zeolite) and, thus, to convert gaseous $\mathrm{SO}_{2}$ to particulate sulfate. As the truck speed and the engine load increased, the exhaust temperature also increased to a level that favored the formation of nucleation mode particles. The increase in nucleation mode PM, combined 


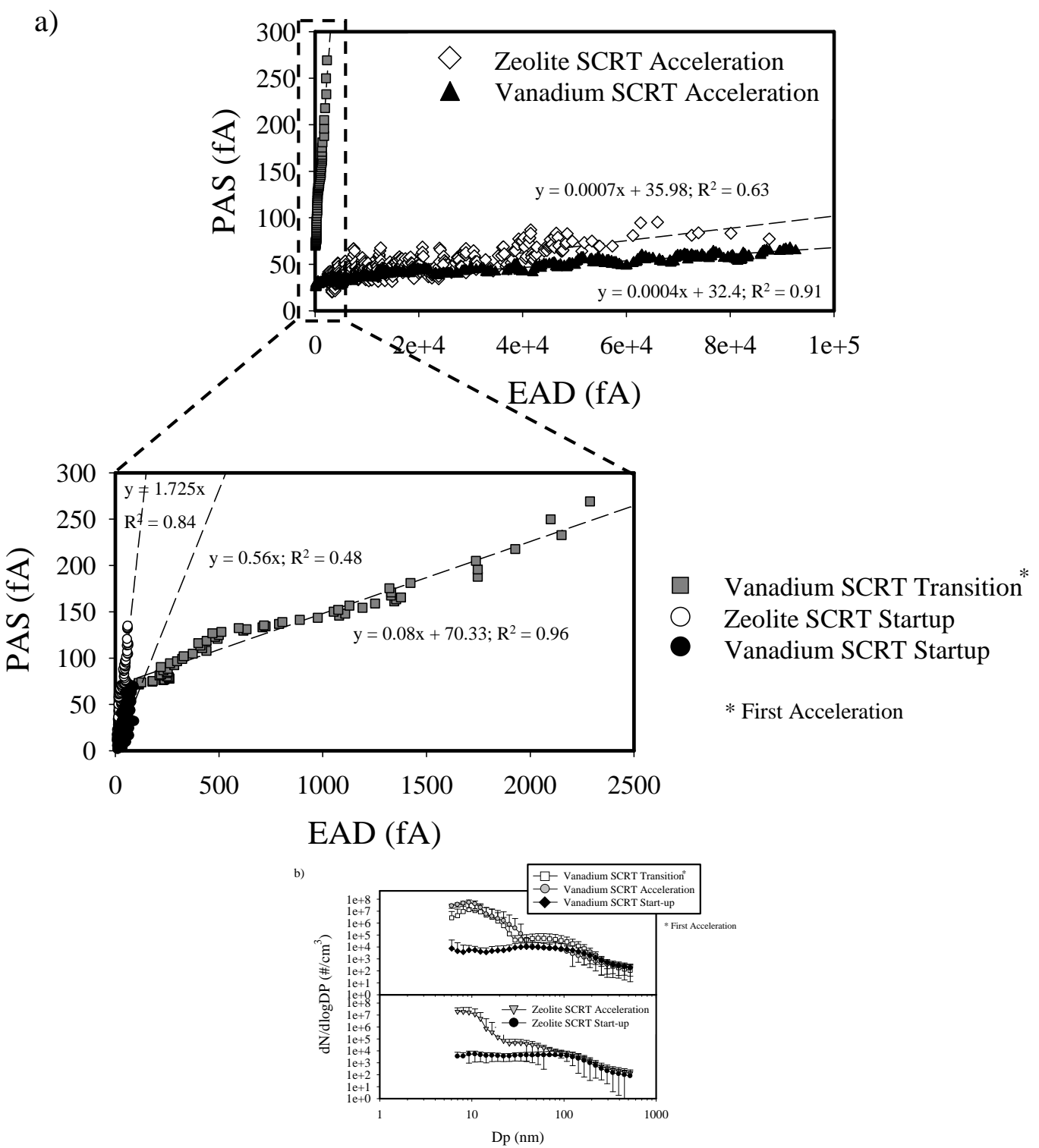

Fig. 6. PAS versus EAD plots for vehicles equipped with SCRT emission control technologies and operating in UDDS mode. Figures show data segregated by different driving modes (a), and the particle size distribution for each driving condition (b).

with the fact that at higher engine loads soot particles are very efficiently captured by the emission control device of a vehicle, contributed to lower the PAS signal (hence emissions of p-PAHs) as the UDDS cycle progressed. These findings are consistent with those reported by Bukowiecki et al. (2002) during other chassis dynamometer tests conducted on diesel vehicles.

It should be noted that throughout our experiments with trucks equipped with SCRT systems, only measurements obtained during the UDDS cycle showed PAS and EAD signals significantly above background levels. When the same vehicles were operated in cruise cycle the PAS current was always close to zero (data not shown), because the size distribution was dominated by nucleation mode particles, which suppress the PAS signal. In addition, during the cruise cycle the exhaust temperatures were sufficiently high to favor an optimal operation of the emission control systems, thus reducing the amount of p-PAHs released.

\subsection{Estimated p-PAH concentrations in Wilmington}

compound. The PAS signal measured in Wilmington was calibrated against the sum of the concentrations of the most abundant p-PAHs obtained from GC/MS analyses of extracts from 10 integrated filter samples collected in June 2007. The correlation between 24-h average PAS signals (fA) and the corresponding sum of the analyzed 


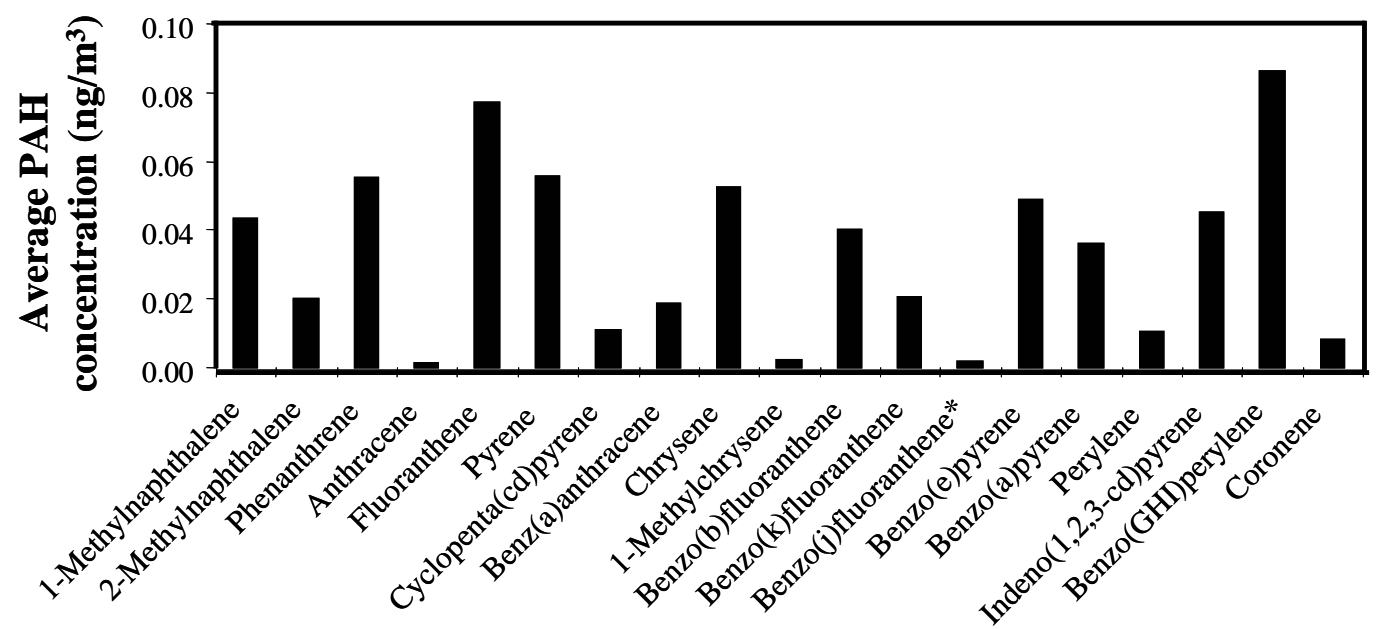

Fig. 7. Relative abundances of individual p-PAHs analyzed by GC/MS in Wilmington. Only those species with concentrations above the detection limit were reported (integrated filter samples were also analyzed for Acenaphthene, Fluorene, 2,6-Dimethylnaphthalene, Retene, Dibenzo(ah)anthracene, Picene, and Dibenzo(ae)pyrene).

p-PAHs $\quad\left(\mathrm{ng} / \mathrm{m}^{3}\right) \quad$ was excellent $\quad\left(R^{2}=0.9 ; \quad\right.$ Slope $=17.5$; Intercept $=-1.33)$, and the resulting estimated concentrations (Average $=0.64 \mathrm{ng} / \mathrm{m}^{3} ; \quad \operatorname{Min}=0.24 \mathrm{ng} / \mathrm{m}^{3} ; \quad \operatorname{Max}=3.05 \mathrm{ng} / \mathrm{m}^{3}$; Standard deviation $=0.46 \mathrm{ng} / \mathrm{m}^{3}$ ) were in good agreement with those reported in previous studies conducted in Los Angeles in similar time periods (Schauer et al., 1996; Manchester-Neelvsg, 2003; Ning et al., 2007). For example, in the summer of 2006 Ning et al. (2007) reported that the average mass concentrations of total p-PAHs measured outside the University of Southern California (USC) campus ( $\sim 150 \mathrm{~m}$ from the I-110 freeway) were 1.93 and $0.49 \mathrm{ng} / \mathrm{m}^{3}$ in the morning and afternoon, respectively. Hourly-averaged p-PAH concentrations estimated in Wilmington were 1.18 and $0.38 \mathrm{ng} / \mathrm{m}^{3}$ at $08: 00$ and 17:00, respectively. The slightly lower p-PAH concentrations of this study are probably due to the fact that our sampling site was located farther from both the I-110 ( $\sim 1.5 \mathrm{Km}$ east) and the I-710 $(\sim 4.5 \mathrm{Km}$ west $)$ freeways compared to the site at USC.

Ambient concentrations of p-PAHs in Los Angeles are much lower than those detected in other metropolitan areas. For example, Marr et al. (2006) reported that in April 2003 ambient p-PAHs in Mexico-City peaked at $\sim 110 \mathrm{ng} / \mathrm{m}^{3}$ during the morning rush hour and rapidly decayed to $\sim 20 \mathrm{ng} / \mathrm{m}^{3}$ in the afternoon because of changes in source activity patterns and dilution as the boundary layer rises. Overnight concentrations were as high as $50 \mathrm{ng} / \mathrm{m}^{3}$, probably because of condensation of gas-phase PAHs onto existing particles driven by temperature decrease. Interestingly, in MexicoCity the surface concentration of p-PAH (measured by a PAS) decreased more rapidly than the bulk PAH concentration (detected by an AMS) during the late morning, suggesting that freshly emitted combustion-related particles were quickly coated by non-photo-emitting secondary aerosol material (organic and inorganic), and that p-PAHs might have been transformed/lost by heterogeneous reactions with oxidants such as $\mathrm{OH}$, ozone, nitrogen oxides, and nitric acid (photolysis may also be an important sink for p-PAHs) (Marr et al., 2006).

The distribution of p-PAH species varies significantly with season, location, and the relative source contributions, especially those from gasoline- and diesel-fuelled vehicles. Figure 7 illustrates the relative abundances of the individual p-PAHs analyzed by GC/MS; only those species with concentrations above the detection limit were reported. Previous roadway tunnel and dynamometer studies (Miguel et al., 1998; Marr et al., 1999; Zielinska et al., 2004; Phuleria et al., 2006; Ning et al., submitted) have shown that diesel vehicle emissions are enriched in lower molecular weight PAHs (e.g., phenantrene and alkylated phenanthrenes, fluoranthene, and chrysene), whereas higher molecular weight PAHs are associated with gasoline vehicle emissions (e.g., benzo(ghi)perylene, indeno[1,2,3-cd]pyrene, and coronene). The presence of relatively high concentrations of both low and high molecular weight p-PAHs in the filter samples suggests that contributions from gasoline- and diesel-powered vehicles (from the I-110 and the I-710, respectively) were both important. Non-negligible concentrations of methylnapthalene and methylchrysene (probably from unburned diesel fuel; Marr et al., 2006) were also detected in Wilmington. Retene, a semi-volatile PAH that originates predominately from the combustion of wood from conifer trees, and is considered to be a tracer for soft wood combustion, was not present in any of the analyzed samples. Because the energy associated with the PAS lamp $(6.0 \mathrm{eV})$ is less than the ionization energy of solid-phase naphthalene $(6.4 \mathrm{eV})$ (Seki, 1989), the instrument does not detect this. 


\subsection{Photo-electric activity and molecular weight/structure}

To improve our understanding on how the PAS signal responds to different p-PAHs deposited on the particle surface, and to investigate which class of PAH contributes the most to the sensor signal, we plotted the concentrations $\left(\mathrm{ng} / \mathrm{m}^{3}\right)$ of individual p-PAHs against the corresponding 24-h average PAS signals. The data-points (Fig. 8) include only species for which the $R^{2}$ was higher that 0.7 ; all other detected p-PAHs were not considered in this discussion. The relationship between photo-electric activity and molecular structure, as well as to microstructure (molecular packing) of the particle/adsorbate system is evident. Our results indicate that the larger the molecule, the higher its probability to be photo-ionized by one photon (because of the larger cross-section). With a few exceptions (phenanthrene and chrysene in particular), the regression slope was the lowest for Methylnaphtalene (slope=188.3; MW=142.2) and increased with the molecular weight of the considered species to a maximum value for Benzo $(e)$ pyrene (slope=939.8; $\mathrm{MW}=252.3$ ). As suggested by Niessner (1986) the degree of molecular packing of PAH molecules in a crystallitic arrangement also affects the intensity of the photo-electric activity. In fact, the regression slopes of Perylene and Benzo (e) pyrene (both characterized by a $\mathrm{MW}=252.3$ and by a rather "packed" molecular structure) were higher than those of $\operatorname{Benzo}(b)$ fluoranthene and $\operatorname{Benzo}(k)$ fluoranthene (2 isomers also having a $\mathrm{MW}=252.3$ but characterized by a more "linear" structure). It appears that the lower the separation distance between aromatic rings (i.e., the higher the degree of packing), the higher the adsorbate-substrate interaction and the resulting photo-electric activity (Niessner, 1986). However, in urban environments, the intensity of the PAS response is also influenced by the presence or absence of secondary inorganic or organic aerosols that could decrease the PAS signal by shielding surface-bound PAHs from detection by photo-ionization (Marr et al., 2006). Keeping this caveat in mind, the relationship between the PAS signal and the PAH molecular structure appears nonetheless to be remarkably consistent, as evidenced in the data plotted in Fig. 8.

\subsection{Lung-cancer Risk in the Wilmington Area}

Because of their mutagenic and carcinogenic properties, exposure to $\mathrm{BC}$, diesel exhaust particles, and p-PAHs may pose a severe health risk to individuals living in the Wilmington area. Estimating the potential health risk from these species and comparing the results to those obtained in other metropolitan areas is instructive, despite the large uncertainties involved in these calculations. Following the procedure adopted by Sauvain et al. (2003) we determined the lungcancer risk associated with exposure to p-PAHs and BC from diesel combustion particles (DCPs). The most common approach for estimating health-risks posed by multi-component p-PAH exposure is based on the individual compound's po-

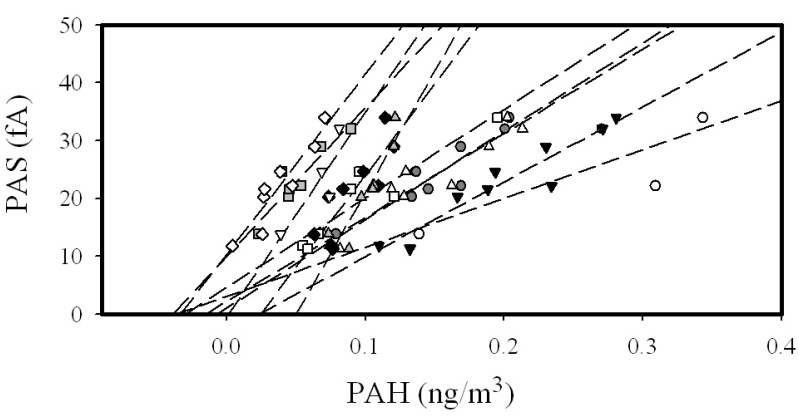

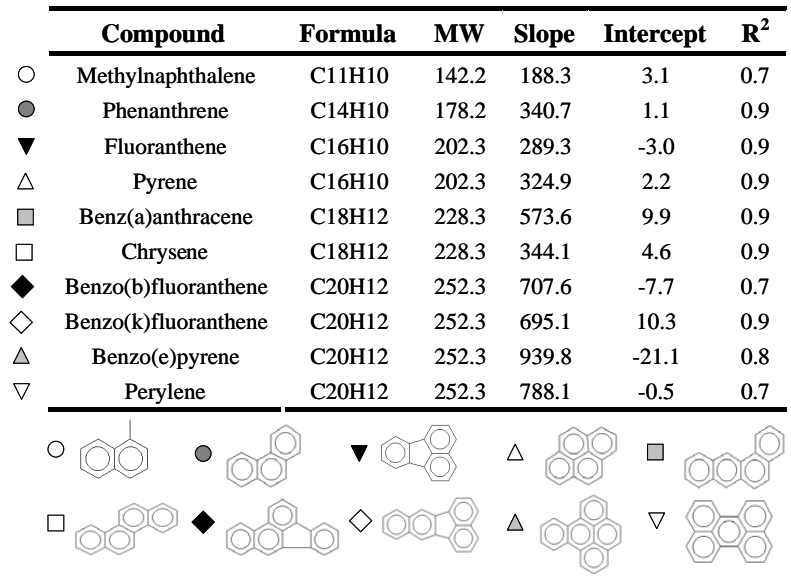

Fig. 8. Concentrations of individual p-PAHs detected by GC/MS analyses of integrated filter samples collected in Wilmington in June 2007 against the corresponding 24-h average PAS signal. Slopes and intercepts of all regression equations, and molecular formulas and structures of each individual species are also reported

tency equivalence factor (PEF) relative to Benzo $(a)$ pyrene $(\mathrm{B}(a) \mathrm{p}$; considered as a toxicological prototype for all other p-PAHs). A B $(a) \mathrm{P}$ equivalent concentration ( $\mathrm{B}(a) \mathrm{Peq})$ is calculated by multiplying the individual p-PAH concentrations by the correspondent PEF (Bostrom et al., 2002; Sauvain et al., 2003; Chen and Liao, 2006), and the carcinogenic potency of all considered p-PAHs is then expressed as the sum of each individual $\mathrm{B}(a) \mathrm{Peq}\left(\sum \mathrm{B}(a) \mathrm{Peq}\right)$. To simplify our calculations, BC was assumed to be emitted only from DCPs. Although this last assumption might not be completely true (a non-negligible fraction of $\mathrm{BC}$ is also released from gasoline vehicles, power plants, and biomass burning; Schauer et al., 2003), it is likely that most of the BC in the Wilmington area is emitted from diesel combustion sources. The theoretical lung-cancer risk due to inhalation of p-PAHs and $\mathrm{BC}$ was then calculated by multiplying the $\sum \mathrm{B}(a) \mathrm{Peq}$ and $\mathrm{BC}$ concentrations by the corresponding unit risk factors, here defined as the risk corresponding to a lifetime (70 years per 24-h per day) exposure to $1 \mu \mathrm{g} / \mathrm{m}^{3}$ of $\sum \mathrm{B}(a) \mathrm{Peq}$ or $\mathrm{BC}$. The lifetime unit risk factor estimates considered in this work were obtained from both epidemiological studies and research conducted on rats (Sauvain et al., 2003), and compared reasonably well with those reported by the World 
Table 3. Approximate theoretical lifetime (70 years per 24-h/day) lung-cancer risk in the Wilmington area due to inhalation of multicomponent p-PAHs and BC. Estimations of the contribution of the p-PAHs (genotoxic) risk to the total lung-cancer risk attributable to BC are also included.

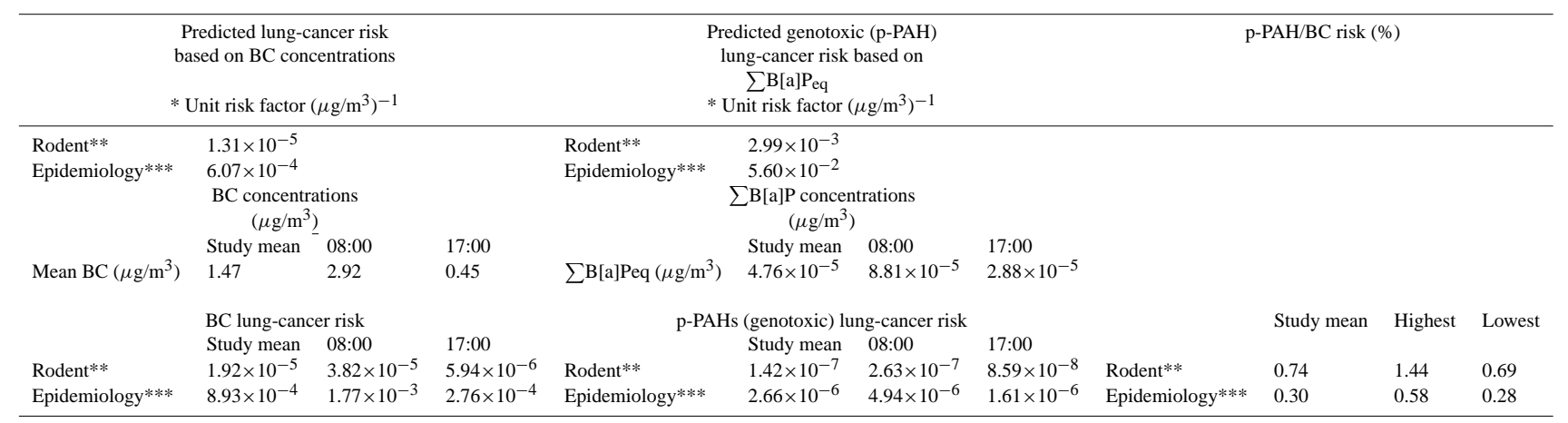

*defined as the risk corresponding to an average lifetime exposure (70 years per $24-\mathrm{h} / \mathrm{day})$ to $1 \mu \mathrm{g} / \mathrm{m}^{3}$ of $\mathrm{BC}$ or $\mathrm{B}(a) \mathrm{P}$. Our values are proportionally higher than those reported by Sauvain et al. (2003) for occupational exposure (45 years per 8 -hr/day) to $1 \mu \mathrm{g} / \mathrm{m}^{3}$ of diesel emission particles or $\mathrm{B}(a) \mathrm{P}$ from diesel exhaust. **lifetime unit risk factor estimated from research conducted on rats; ***lifetime unit risk factor estimated from epidemiological studies. Note: the lifetime unit risk factor for exposure to total-p-PAHs reported by the World Health Organization for coke oven workers is $8.70 \times 10^{-2}$ (WHO: Air Quality Guidelines for Europe, 2000).

Health Organization for coke oven workers (WHO: Air Quality Guidelines for Europe, 2000).

The results of these rather simplified risk calculations (Table 3) highlight two important points. First, the lungcancer risk at the Wilmington site is highest during rush hour traffic (at 08:00; Risk[BC] $=3.82 \times 10^{-5}$ for the rodentbased estimate to $1.77 \times 10^{-3}$ for the epidemiologic estimate; Risk $[\mathrm{p}-\mathrm{PAHs}]=2.63 \times 10^{-7}$ for the rodent-based estimate to $4.94 \times 10^{-6}$ for the epidemiologic estimate) and lowest in the afternoon (at 17:00, Risk[BC] $=5.94 \times 10^{-6}$ to $2.76 \times 10^{-4}$; Risk $[\mathrm{p}-\mathrm{PAHs}]=8.59 \times 10^{-8}$ to $\left.1.61 \times 10^{-6}\right)$. Secondly, the genotoxic risk of the considered p-PAHs does not seem to contribute to a significant part of the total lung-cancer risk attributable to BC (less than 2\%). For comparison, Sauvain et al. (2003) estimated that the lifetime risk of lung cancer associated with occupational exposure to p-PAHs measured in a bus depot, a truck repair workshop, and an underground tunnel in Lausanne (Switzerland), was 3 to $8 \%$ of the total risk attributable to diesel exhaust particles emitted in the summertime. Marr et al. (2004) calculated a mean cancer risk level for p-PAHs of approximately $5 \times 10^{-5}$ (a value $\sim 10$ times higher than the highest p-PAH risk estimated in Wilmington) for lifetime exposure to p-PAHs concentrations found along a typical roadway in the Mexico-City metropoli$\tan$ area. Although these calculations are rather uncertain and highly dependent on the sampling location and season (in the summer a higher percentage of semi-volatile PAHs is present in the gaseous phase), they suggest that the risk associated with inhalation to p-PAHs and BC is the highest along roadways and in areas characterized by fresh vehicle emissions, and decreases with increasing distance from the roadways. This hypothesis is further validated by considering that the maximum PAS signal (fA) measured for the "baseline" vehicle during our dynamometer tests was more than 250 times higher than the maximum ambient PAS measurements (fA) recorded in Wilmington. The health effects associated with exposure to other carcinogenic compounds present in the atmosphere (e.g. nitro-PAHs and other organic compounds), may further amplify this risk.

\section{Conclusions}

The photo-electric aerosol sensor (PAS) was used in conjunction with other continuous instruments to provide information on p-PAH emissions a) in Wilmington (CA), near the Los Angeles port and close the I-110 and I-710 freeways, and b) from 3 diesel trucks with and without emission control technologies (SCRT and "baseline" vehicles, respectively). Ambient concentrations of p-PAHs peaked between 09:00 and 11:00 (along with those of particle surface area, $\mathrm{PN}$, and $\mathrm{BC}$ ) because of increased contributions from both gasoline- and diesel-fuelled vehicles, and were 4 times higher than later in the afternoon. The observed changes in the chemical and physical properties of p-PAHs throughout the day suggest that the toxicity of fresh versus aged particles may differ. In particular, the bioavailability of p-PAHs is likely to be the highest during rush hour traffic, when fresh combustion particles are not coated with other non photoemitting compounds. p-PAH emissions from the "baseline" vehicle were up to 200 times higher than those from the SCRT trucks, and increased when the vehicle was accelerating. The highest PAS readings for SCRT trucks were obtained at start-up, probably because the engine temperature was not high enough to activate the catalyst (Vanadium or 
Zeolite). Total p-PAHs concentrations in Wilmington (Average $=0.64 \mathrm{ng} / \mathrm{m}^{3} ;$ Min $=0.24 \mathrm{ng} / \mathrm{m}^{3} ;$ Max $=3.05 \mathrm{ng} / \mathrm{m}^{3} ;$ Standard deviation $=0.46 \mathrm{ng} / \mathrm{m}^{3}$ ) were in good agreement with those reported in previous studies conducted in Los Angeles in similar time periods, but much lower than those detected in other metropolitan areas such as Mexico-city (p$\mathrm{PAH} \sim 110 \mathrm{ng} / \mathrm{m}^{3}$ during morning rush hour; Marr et al., 2004, 2006). Finally, estimations of the theoretical lifetime (70 years per 24-h/day) lung-cancer risk in Wilmington associated with exposure to p-PAHs and BC from diesel combustion particles revealed that the lung-cancer risk is highest during rush hour traffic (at 08:00; Risk $[\mathrm{BC}]=3.82 \times 10^{-5}$ to $1.77 \times 10^{-3}$; Risk $[\mathrm{p}-\mathrm{PAHs}]=2.63 \times 10^{-7}$ to $4.94 \times 10^{-6}$ ) and lowest in the afternoon (at 17:00, Risk[BC] $=5.94 \times 10^{-6}$ to $2.76 \times 10^{-4}$; Risk[p-PAHs] $=8.59 \times 10^{-8}$ to $1.61 \times 10^{-6}$ ). It is reasonable to assume that commuters spending several hours per day on the I-110 and the I-710 face an even higher lungcancer risk than individuals living around the Wilmington area due to prolonged exposure to higher concentrations of p-PAHs and BC.

Acknowledgements. This research was supported by the Southern California Particle Center (SCPC), funded by EPA under the STAR program through Grant RD-8324-1301-0 to the University of Southern California. The research described in this work has not been subjected to the agency's required peer and policy review and therefore does not necessarily reflect the views of the agency, and no official endorsement should be inferred. Mention of trade names or commercial products does not constitute an endorsement or recommendation for use.The authors would like to thank the California Air Resource Board for their fundamental help with the dynamometer tests, J. Quintana of the Division of Occupational and Environmental Health at San Diego State University for providing the 2 photo-electric aerosol sensors, the South Coast Air Quality Management District for their important contributions to the field campaign, and M. Olson and J. Schauer at the Wisconsin State Laboratory of Hygiene for sample preparation and chemical analysis.

Edited by: C. Chan

\section{References}

Ayala, A., Kado, N. Y., Okamoto, R. A., Holmen, B. A., Kuzmicky, P. A., Kobayashi, R., Stiglitz, K. E. Diesel and CNG Heavy-duty Transit Bus: Emissions over Multiple Driving Schedules: Regulated Pollutants and Project Overview, Journal of Lubricants and Fuels, SAE Transactions, 111, 735-747, 2002.

Baltensperger, U., Streit, N., Weingartner, E., Nyeki, S., Prevot, A. S. H., Van Dingenen, R., Virkkula, A., Putaud, J. P., Even, A., et al.: Urban and rural aerosol characterization of summer smog events during the PIPAPO field campaign in Milan, Italy, J. Geophys. Res.-Atmos., 107(D22), 8193, doi:10.1029/2001JD001292, 2002.

Bostrom, C.-E., Gerde, P., Hanberg, A., Jernstrom, B., Johansson, C., Kyrklund, T., Rannug, A., Tornqvist, M., Victorin, K., and Westerholm, R.: Cancer Risk Assessment, Indicators, and Guidelines for Polycyclic Aromatic Hydrocarbons in the Ambient Air, Environ. Health Persp., 110, 451-489, 2002.

Bukowiecki, N., Kittelson, D. B., Watts, W. F., Burtscher, H., Weingartner, E., and Baltensperger, U.: Real-time characterization of ultrafine and accumulation mode particles in ambient combustion aerosols, J. Aerosol Sci., 33(8) 1139-1154, 2002.

Chen, S.-C. and Liao, C.-M.: Health risk assessment on human exposed to environmental polycyclic aromatic hydrocarbons pollution sources, Sci. Total Environ., 366 112-123, 2006.

Chetwittayachan, T., Shimazaki, D., and Yamamoto, K. A.: A comparison of temporal variation of particle-bound polycyclic aromatic hydrocarbons (pPAHs) concentration in different urban environments: Tokyo, Japan, and Bangkok, Thailand, Atmos. Environ., 36(12), 2027-2037, 2002.

Cho, A. K., Sioutas, C., Miguel, A. H., Kumagai, Y., Schmitz, D. A., Singh, M., Eiguren-Fernandez, A., and Froines, J. R.: Redox activity of airborne particulate matter at different sites in the Los Angeles Basin, Environ. Res., 99(1), 40-47, 2005.

Code of Federal Regulations, Vol. 40 CFR, Subpart M, 86.121585, Web-site: http://www.epa.gov/OMS/regs/hd-hwy/2000frm/ 2004frm.pdf, 2004.

Dunbar, J. C., Lin, C.-I., Vergucht, I., Wong, J., and Durant, J. L.: Estimating the contributions of mobile sources of PAH to urban air using real-time PAH monitoring, The Science of the Total Environment 279, 1-19, 2001.

Ferge, T., Maguhn, J., Hafner, K., Muhlberger, F., Davidovic, M., Warnecke, R., Zimmermann, R. On-line analysis of gas-phase composition in the combustion chamber and particle emission characteristics during combustion of wood and waste in a small batch reactor, Environ. Sci. Technol., 39(6), 1393-1402, 2005.

Fissan, H., Neumann, S.,Trampe, A., Pui, D. Y. H., and Shin, W. G.: Rationale and Principle of an Instrument Measuring Lung Deposited Nanoparticle Surface Area, J. Nanopart. Res., 9, 5359, 2007.

Fujita, E. M., Campbell, D. E., Arnott, W. P., Chow, J. C., and Zielinska, B.: Evaluations of the chemical mass balance method for determining contributions of gasoline and diesel exhaust to ambient carbonaceous aerosols, Journal of the Air and Waste Management Association, 57(6), 721-740, 2007.

Harrison, R. M., Smith, D. J. T., and Luhana, L.: Source apportionment of atmospheric polycyclic aromatic hydrocarbons collected from an urban location in Birmingham, UK, Environ. Sci. Technol., 30(3), 825-832, 1996.

Hart, K. M., McDow, S. R., Giger, W., Steiner, D., and Burthscher, H.: The correlation between in-situ, real-time aerosol photoemission intensity and particulate polycyclic aromatic hydrocarbon concentration in combustion aerosols, Water, Air, Soil Pollution, 68, 75-90, 1993.

Herndon, S. C., Onasch, T. B., Frank, B. P., Marr, L. C., Jayne, J. T., Canagaratna, M. R., Grygas, J., Lanni, T., Anderson, B. E., Worsnop, D., and Miake-Lye, R. C.: Particulate emissions from in-use commercial aircraft, Aerosol Sci. Tech., 39(8), 799-809, 2005.

International Agency for Research on Cancer (IARC, 2005), Overall Evaluations of Carcinogenicity to Humans (World Health Organization), IARC website: www.iarc.fr.

Jimenez, J. L., Jayne, J. T., Shi, Q., Kolb, C. E., Worsnop, D. R., Yourshaw, I., Seinfeld, J. H., Flagan, R. C., Zhang, X., Smith, 
K. A., Morris, J., and Davidovits, P.: Ambient aerosol sampling with an aerosol mass spectrometer, J. Geophys. Res., 108, 84258438, 2003.

Jung, H. and Kittelson, D. B.: Characterization of Aerosol Surface Instruments in Transition Regime, Aerosol Sci. Technol., 39, 902-911, 2005.

Kelly, K., Wagner, D., Lighty, J., Nunez, M. Q., Vazquez, F. A., Collins, K., and Barud-Zubillaga, A.: Black carbon and polycyclic aromatic hydrocarbon emissions from vehicles in the United States-Mexico border region: Pilot study, Journal of the Air and Waste Management Association, 56 (3), 285-293, 2006.

Manchester-Neesvig, J. B., Schauer, J. J, and Cass, G.: The Distribution of Particle-Phase Organic Compounds in the Atmosphere and Their Use for Source Apportionment during the Southern California Children's Health Study, Journal of Air and Waste Management Association, 53, 1065-1079, 2003.

Marr, L. C., Kirchstetter, T. W., Harley, R. A., Miguel, A. H., Hering, S. V., and Hammond, S. K. Characterization of polycyclic aromatic hydrocarbons in motor vehicle fuels and exhaust emissions, Environ. Sci. Technol., 33(18), 3091-3099, 1999.

Marr, L. C., Grogan, L. A., Wohrnschimmel, H., Molina, L. T., Molina, M. J., Smith, T. J., and Garshick, E.: Vehicle traffic as a source of particulate polycyclic aromatic hydrocarbon exposure in the Mexico City metropolitan area, Environ. Sci. Technol., 38(9), 2584-2592, 2004.

Marr, L. C., Dzepina, K., Jimenez, J. L., Reisen, F., Bethel, H. L., Arey, J., Gaffney, J. S., Marley, N. A., Molina, L. T., and Molina, M. J.: Sources and transformations of particle-bound polycyclic aromatic hydrocarbons in Mexico City, Atmos. Chem. Phys., 6, 1733-1745, 2006,

http://www.atmos-chem-phys.net/6/1733/2006/.

Matter, U., Siegman, H. C., and Burtscher, H.: Dynamic Field Measurements of Submicron Particles from Diesel engines, Environ. Sci. Technol., 33, 1946-1952, 1999.

Miguel, A. H., Kirchstetter, T. W., Harley, R. A., and Hering, S. V.: On-road emissions of particulate polycyclic aromatic hydrocarbons and black carbon from gasoline and diesel vehicles, Environ. Sci. Technol., 32(4), 450-455, 1998.

McDow, S. R., Giger, W., Burthscher, H., Schmidt-Ott, A., and Siegmann, H. C. Polycyclic aromatic hydrocarbons and combustion aerosol photoemission, Atmos. Environ., 24A, 2911-2916, 1990.

Naumova, Y. Y., Offenberg, J. H., Eisenreich, S. J., Meng, Q., Polidori, A., Turpin, B. J., Weisel, C. P., Morandi, M. T., Colome, S. D., Stock, T. H., Winer, A. M., Alimokhtari, S., Kwon, J., Maberti, S., Shendell, D., Jones, J., and Farrar, C.: Gas/particle distribution of polycyclic aromatic hydrocarbons in coupled outdoor/indoor atmospheres, Atmos. Environ., 37, 703-719, 2003.

Nel, A.: Air pollution-related illness: effects of particles, Science, 309(5739), 1326-1326, 2005.

Niessner, R.: The Chemical Response of the Photo-Electric Aerosol Sensor (PAS) to Different Aerosol Systems, J. Aerosol Sci., 17(4), 705-714, 1986.

Ning, Z., Geller, M. D., Moore, K. F., Sheesley, R., Schauer, J. J., and Sioutas, C.: Daily variation in chemical characteristics of urban ultrafine aerosols and inference of their sources, Environ. Sci. Technol., 41(17), 6000-6006, 2007.

Ning, Z., Polidori, A., Schauer, J. J., and Sioutas, C.: Light- and Heavy-Duty Vehicle Emission Factors of PM species Based on
Freeway Measurements and Comparison with Tunnel and Dynamometer Studies, submitted for publication to Atmos. Environ., in press, 2008.

Ntziachristos, L., Ning, A., Geller, M. D., Sheeseley, R. J., Schauer, J. J., and Sioutas, C.: Fine, ultrafine and nanoparticle trace element compositions near a major freeway with a high heavy-duty diesel fraction, Atmos. Environ., 41, 5684-5696, $2007 \mathrm{a}$.

Ntziachristos, L., Ning, Z., Geller, M. D., and Sioutas, C.: Particle concentration and characteristics near a major freeway with heavy-duty diesel traffic, Environ. Sci. Technol., 41(7), 22232230, $2007 b$.

Ntziachristos, L., Polidori, A., Phuleria, H., Geller, M. D., Sioutas, C. Application of a diffusion charger for the measurement of particle surface concentration in different environments, Aerosol Sci. Technol., 41 (6), 571-580, 2007c.

Ott, W. R. and Siegmann, H. C.: Using multiple continuous fine particle monitors to characterize tobacco, incense, candle, cooking, wood burning, and vehicular sources in indoor, outdoor, and in-transit settings, Atmos. Environ., 40, 821-843, 2006.

Phuleria, H. C., Geller, M. D., Fine, P. M., and Sioutas, C.: Sizeresolved emissions of organic tracers from light-and heavy-duty vehicles measured in a California roadway tunnel, Environ. Sci. Technol., 40(13), 4109-4118, 2006.

Pope, C. A., Burnett, R. T., Thun, M. J., Calle, E. E., Krewski, D., Ito, K., and Thurston, G. D.: Lung cancer, cardiopulmonary mortality, and long-term exposure to fine particulate air pollution, J. Am. Med. Assoc., 287(9), 1132-1141, 2002.

Pope, C. A., Burnett, R. T., Thurston, G. D., Thun, M. J., Calle, E. E., Krewski, D., and Godleski, J. J.: Cardiovascular mortality and long-term exposure to particulate air pollution - Epidemiological evidence of general pathophysiological pathways of disease, Circulation, 109 (1) 71-77, 2004.

Riddle, S. G., Robert, M. A., Jakober, C. A., Hannigan, M. P., and Kleeman, M. J.: Size Distribution of Trace Organic Species Emitted from Heavy-Duty Diesel Vehicles, Environ. Sci. Technol., 41(6), 1962-1969, 2007a.

Riddle, S. G., Jakober, C. A., Robert, M. A., Cahill, T. M., Charles M. J. and Kleeman, M. J.: Large PAHs detected in fine particulate matter emitted from light-duty gasoline vehicles, Atmos. Environ., 41(38), 8658-8668, doi:10.1016/j.atmosenv.2007.07.023, 2007b.

Rogers, F., Arnott, P., Zielinska, B., Sagebiel, J., Kelly, K. E., Wagner, D., Lighty, J. S., and Sarofim, A. F.: Real-time measurements of jet aircraft engine exhaust, Journal of the Air and Waste Management Association, 55(5), 583-593, 2005.

Sauvain, J. J., Duc, T. V., and Guillemin, M.: Exposure to carcinogenic polycyclic aromatic compounds and health risk assessment for diesel-exhaust exposed workers, International Archives of Occupational and Environmental Health, 76(6), 443-455, 2003.

Schauer, J. J., Rogge, W. F., Hildemann, L. M., Mazurek, M. A., and Cass, G. R.: Source apportionment of airborne particulate matter using organic compounds as tracers, Atmos. Environ., 30(22) 3837-3855, 1996.

Schauer, J. J., Kleeman, M. J., Cass, G. R., and Simoneit, B. R. T.: Measurement of emissions from air pollution sources, 2. C1 through C-30 organic compounds from medium duty diesel trucks, Environ. Sci. Technol., 33(10), 1578-1587, 1999.

Schauer, J. J., Kleeman, M. J., Cass, G. R., and Simoneit, B. R. T.: Measurement of emissions from air pollution sources, 5. C1- 
C32 organic compounds from gasoline-powered motor vehicles, Environ. Sci. Technol., 36, 1169-1180, 2002.

Schauer, J. J.: Evaluation of elemental carbon as a marker for diesel particulate matter, Sci. Total Environ., 366, 112-123, 2003.

Siegmann, K. and Siegmann, H. C.: Fast and reliable "in situ" evaluation of particles and their surfaces with special reference to diesel exhaust, SAE Technical Paper Series, 2000-01-1995, 1-7, 2000.

Sheesley, R. J., Schauer, J. J., Smith N. D., and Hays M. D.: Development of a standardized method for the analysis of organic compounds present in $\mathrm{PM}_{2.5}$, in: Proceedings of the AWMA Annual Meeting 2000, Salt Lake City, UT, 2000.

Sheesley, R. J., Schauer, J. J., Bean, E., and Kenski, D.: Trends in secondary organic aerosol at a remote site in Michigan's upper peninsula, Environ. Sci. Technol., 38(24), 6491-6500, 2004.

Wallace, L.: Real-Time Measurements of Black Carbon Indoors and Outdoors: A Comparison of the Photoelectric Aerosol Sensor and the Aethalometer, Aerosol Sci. Technol., 39, 1015-1025, 2005.
Wasserkort, R., Hartmann, A., Widmer, R. M., and Burthscher, H.: Correlation between on-line PAH detection in airborne particle samples and their bacterial genotoxicity, Ecotox. Environ. Safe., 40, 126-136, 1996.

World Health Organization (WHO): Air Quality Guidelines for Europe, 2000. Website: http://www.euro.who.int/air.

Zhiqiang, Q., Siegmann, K., Keller, A., Matter, U., Scherrer, L., and Siegmann, H.C.: Nanoparticle air pollution in major cities and its origin, Atmos. Environ., 34, 443-451, 2000.

Zielinska, B., Sagebiel, J., McDonald, J. D., Whitney, K. and Lawson,D. R.: Emission rates and comparative chemical composition from selected in-use diesel and gasoline-fueled vehicles, Journal of the Air and Waste Management Association, 54(9), 11381150, 2004. 